\title{
Position paper of the Sri Lanka College of Paediatricians on resuscitation of extremely premature / low birth weight newborns
}

\author{
Sri Lanka Journal of Child Health, 2015: 44(1): 3-11
}

(Key words: Position paper of Sri Lanka College of Paediatricians; resuscitation of extremely premature/low birth weight babies\}

\section{Preamble}

Advancement of neonatal and obstetric care practices in Sri Lanka has improved the care and survival of extremely preterm and extremely low birth weight (ELBW) neonates. Management of an extremely preterm infant is challenging in many aspects but when caring for those at the limit of viability, the more premature the baby, greater is the mortality and greater the incidence of neurological disability in survivors.

There are no large scale multi-centre studies which have specifically looked at gestation based survival and long term outcome of extremely preterm infants in Sri Lanka. The data we quote are based on studies in Western countries where facilities for caring for these infants are more freely available. However, in Sri Lanka, and even in those countries, each pregnancy, mother, infant and particular unit, together with the circumstances under which a baby is born, are unique. There will be variations in survival and outcome depending on those factors.

This position statement is therefore being issued by the Sri Lanka College of Paediatricians (SLCP), after taking into consideration the available scientific evidence, knowledge and technological facilities in Sri Lanka, as a guide to health care personnel who care for extremely preterm infants and their families.

The position statement was formulated by a subcommittee of the SLCP comprising Professor Sujeewa Amarasena, Dr. Srilal de Silva, Dr. Ramya de Silva, Dr. Medha Weerasekera, Dr. Ranmali Rodrigo, Dr. Nishani Lucas and Dr. Nalin Gamaathige

\section{Current situation}

The laws in Sri Lanka have clearly defined criminal abortion and viability. Section 306 of the penal code (as amended) has defined viability as follows ${ }^{1}$ : A fetus is viable after 28 weeks of gestation.

For purposes of calculation, the period of amenorrhoea on the basis of mothers' last regular menstrual period
(LRMP) is taken as period of gestation. Birth weight is not used in the penal code.

\section{Assessing the maturity}

Maturity is not the same as gestational age or size of the baby. Assessing the maturity of a fetus or newborn is complex and difficult as it involves many organ systems and each system might not be equally mature.

As per the National Academy of Sciences, USA ${ }^{2}$ :

- Neither gestational age nor birth weight is a sufficient or complete indicator of the level of immaturity of a newborn.

- Birth weight is an incomplete surrogate for gestational age for determination of the risk of perinatal morbidity and mortality.

- There are several methods of assessing gestational age ranging from last menstrual period of the mother on maternal recall to obstetric ultrasound, anthropometric measurements of the baby once it is born and examination of physical characteristics and neurological assessment postnatally.

In Sri Lanka, the mother's LRMP is the most widely used criterion for estimating gestation and maturity. Obstetric ultrasound scans, performed specifically for determination of gestational age, are not universally done at present. Due to the well-known unreliability of using LRMP to estimate gestational age, we suggest that the birth weight is also used, in practical terms, in deciding the maturity and in certain situations the appropriateness of offering resuscitation to an extremely preterm infant.

Although ultrasound scanning facilities are widely available in Sri Lanka, early dating scans may not have been done in all women who present in labour at gestations close to the limits of viability. Even with early dating scans there is a possible margin of error, 
according to the American College of Obstetricians and Gynaecologists Committee on Obstetric Practice ${ }^{3}$ :

- It is reported that only half of women can actually recall their exact LRMP.

- Ultrasound measurement of the embryo or fetus in the first trimester (up to and including ' $13+6$ ' weeks of gestation) is the most accurate method to establish or confirm gestational age.

- If pregnancy resulted from assisted reproductive technology (ART), the ARTderived gestational age should be used.

- Up to and including ' $13+6$ ' weeks of gestation, gestational age assessment based on measurement of the crown-rump length (CRL) has an accuracy of \pm 5 to 7 days.

- Gestational age assessment by ultrasonography in the first part of the second trimester (between ' $14+0$ ' weeks and ' $21+6$ ' weeks of gestation, inclusive) has an accuracy of \pm 7 to 10 days; between ' $22+0$ ' weeks and ' $27+6$ ' weeks of gestation, ultrasound dating has an accuracy of \pm 10 to 14 days.

- Gestational age assessment by ultrasonography in the third trimester (' $28+0$ ' weeks of gestation and beyond) is the least reliable method, with an accuracy of \pm 21 to 30 days.

Hence it is evident that even ultrasonography can give a variable estimate, especially if done later in pregnancy.

\section{'Viability' to decide on resuscitation ${ }^{4}$}

The term 'viability' encompasses an even more important meaning than the above, in many real life situations. 'Viability' as per the Oxford Dictionary is the "ability to live after birth" and the Webster Dictionary defines it as "having attained such form and development as to be normally capable of surviving outside the mother's womb"6. In general, the term 'viability' refers to the gestational age when a fetus reaches an anatomical threshold when critical organs, such as the lungs and kidneys, can sustain life $^{7}$. The Nuffield Council on Bioethics specifically defines the borderline of viability as an infant born at or before the gestational age of 25 weeks ${ }^{8}$. More commonly, the limit of viability has been defined as the age of fetal maturity that ensures a reasonable chance of extra-uterine survival given (the available) technological support ${ }^{9}$.

By Sri Lankan statute the gestational age of viability is 28 weeks. However, most preterm infants (less than 37 completed weeks of gestation ${ }^{10}$ cannot live totally independently and they need support from the mother, health care personnel and sophisticated technology to: breathe, feed, grow and maintain an adequate body temperature. Hence the term viability is only a guideline for the health care workers to provide resuscitation and support to facilitate such newborns live outside the mothers' uterus.

\section{What is a live birth?}

The World Health Organisation definitions are as follows ${ }^{10,11}$ :

Live birth: the complete expulsion or extraction from its mother of a product of conception, irrespective of the duration of the pregnancy, which, after such separation, breathes or shows any other evidence of life e.g. beating of the heart, pulsation of the umbilical cord or definite movement of voluntary muscles, whether or not the umbilical cord has been cut or the placenta is attached. Each product of such a birth is considered live born.

Still birth: A baby born with no signs of life, weighing more than $1000 \mathrm{~g}$ or with more than 28 completed weeks of gestation (for international comparison purposes). This means that each country has the option of categorizing still births using other criteria.

Neonatal death: A death within 28 days of birth of any live-born baby regardless of weight or gestational age

The Sri Lankan law currently categorises babies born at less than 28 weeks with signs of life as live abortions.

Section 306 of the penal code (as amended) of Sri Lanka defines a criminal abortion as follows: A criminal abortion is an "Act done with intent to prevent a child being born alive or to cause it to die after birth and if such act was not done in good faith to save the life of the mother and prevent a child being born alive". (Punishment-10 years or fine or both) 


\section{What is the current situation for babies born at less than 28 weeks of gestation in Sri Lanka?}

As mentioned previously, with the advancement of neonatal care in the country, some preterm babies born at less than 28 weeks gestation do survive. However, morbidity and mortality are still high in this group especially in those below 26 weeks gestation where the mortality rate is $50 \%$ to $100 \%$ according to the limited unpublished data available in Sri Lanka. Hence the provision of care in the absence of a currently applicable legal framework and technical guidelines is at the discretion of the paediatricians, obstetricians and the immediate health care providers caring for each individual baby. However, the professionals involved in the care of such ELBW preterm infants take responsibility to study and follow guidelines in other countries in making decisions regarding care.

Sri Lanka has two circulars issued by the Ministry of Health $(\mathrm{MoH})$ of the Government of Sri Lanka pertaining to extremely preterm infants.

1. General Circular Number 01-19/2011 dated $01 / 07 / 2011$ on the use of surfactant for ELBW preterm infants

2. Feto-infant mortality surveillance in the Colombo District by Family Health Bureau ${ }^{12}$

The first circular advises the use of surfactant on 27 week gestation and more than $900 \mathrm{~g}$ birth weight infants. This circular indirectly admits the poor survival chances of less than 27 week gestation and less than $900 \mathrm{~g}$ birth weight infants. Therefore it does not recommend use of expensive medications like surfactant in ELBW infants who do not fulfil these criteria. It suggests compassionate care for such infants. However recently there have been numerous instances of babies between $600-900 \mathrm{~g}$ birth weight and of gestations lower than 27 weeks surviving with minimal morbidity and for whom surfactant has been used. The recommendation of 27 weeks therefore ignores the legal status that babies less than 28 weeks are considered to be live abortions.

The second circular is on collecting data for feto-infant mortality surveillance and admits directly only those over 27 weeks are considered for calculation of mortality rates and those between 22 to 27 weeks are collected for surveillance purposes only. Therefore the $\mathrm{MoH}$ indirectly suggests the non-viability of less than 27 week gestation infants while accepting that infants of even less gestations are being treated and managed at the discretion of the attending health care personnel.

Therefore there are currently no clear guidelines available for health care providers to follow, when caring for babies less than 27 week gestation in Sri Lanka and professionals need to use their discretion in making decisions on resuscitation and intensive care which when made by qualified personnel, should be steadfastly upheld.

\section{EPICure $1^{13}$ and $2^{14}$}

These were 2 large country-wide studies of outcomes of extremely preterm infants conducted in UK \& Republic of Ireland in 1995 and England in 2006. Mortality and morbidity figures from these studies are shown in Table 1.

Table 1: Survival and disability statistics by gestation from EPICure 1 and EPICure 2 studies (1995-2006)

\begin{tabular}{|c|c|c|c|c|}
\hline & \multicolumn{2}{|c|}{$\begin{array}{c}\text { Survival to discharge (E1) / 3 years } \\
\text { (E2) (\%) }\end{array}$} & \multicolumn{2}{c|}{$\begin{array}{c}\text { Disability in survivors at 30 months (E1) / } \\
\text { 3 years (E2) (\%) }\end{array}$} \\
\hline Gestation (weeks) & EPICure 1 (1995) & EPICure 2 (2006) & EPICure 1 (1995) & EPICure 2 (2006) \\
\hline 22 & 1 & 16 & 50 & 100 \\
\hline 23 & 11 & 29 & 56 & 45 \\
\hline 24 & 26 & 46 & 54 & 30 \\
\hline 25 & 44 & 68 & 46 & 25 \\
\hline 26 & - & 78 & - & 20 \\
\hline
\end{tabular}

E1 $=$ EPICure $1 ; E 2=$ EPICure 2

United Kingdom (UK) has access to very advanced technologies for neonatal care including a neonatal transport system which is available even in remote areas of the country.

\section{Recommendations for clinicians responsible for the care of neonates}

Our recommendations are made considering the ground level realities of obstetric care (mainly availability of accurate dating scans) and neonatal care in Sri Lanka and the findings of the EPICure studies done in UK. We recommend the following guidelines for the management of extremely preterm infants with 
regard to provision of resuscitation and intensive care. It is based on several international guidelines ${ }^{4,15-17}$ while taking into consideration the technological and other health care facilities available in Sri Lanka and the limitations faced by probably not being able to accurately estimate gestational age prenatally. Especially in view of the latter fact and the high incidence of intra-uterine growth restriction in Sri Lanka, we recommend that the antenatally estimated gestational age and birth weight are both used as independent variables in taking decisions on the intensity of support that is to be offered at birth to extremely preterm babies. The weight should not be considered if the baby is hydropic. When estimation of gestational age becomes more accurate in the future with the more widespread use of first trimester dating scans, the following recommendations will need to change, with less emphasis on birth weight.

- For extremely preterm babies whose gestation is thought to be around 24 weeks or more:

- The most senior clinician responsible for the baby should be informed prior to the delivery whenever feasible, so that the clinician will have the opportunity to inform parents of the expected outcomes and plan of management for the baby. Antenatal counselling which prepares the parents for the possibility of, for example, a 22 week infant taking a few gasps after delivery, although ultimate prognosis is very poor, can help to prevent or mitigate many unpleasant situations and legal issues.

- The most senior clinician responsible for the baby should be present at the delivery if feasible or should examine the baby as soon as possible after delivery as there is always the possibility that a baby, expected to be 24 weeks by dates, actually has a physical maturity of 28 weeks.

- In the event of the delivery of a baby whose gestation is estimated to be between ' $24+0$ ' and ' $27+6$ ' weeks, the most senior neonatal /paediatric medical officer (or 2, if feasible) available in the hospital should be present at the delivery, accompanied by an experienced nursing officer from the neonatal unit if possible. The labour room / operating theatre / obstetric and gynaecology staff should assist and provide all necessary support and equipment as required and even commence resuscitation in the event of a delay in the paediatric / neonatal staff being present.

- If these babies are admitted to the neonatal unit, the baby should be accompanied by both the nurse and the medical officer.

- Baby should be weighed soon after birth if they appear to be less than $500 \mathrm{~g}$ or the gestation is uncertain and believed to be around 24 weeks, in order to decide on resuscitation. A weighing scale should therefore be available in gynaecology wards, operating theatres, labour rooms and antenatal wards.

\section{Babies less than ' $24+0$ ' weeks:}

\section{- Babies less than ' $24+0$ ' weeks and with a weight less than $500 \mathrm{~g}$}

$>\quad$ If the baby is expected to be 22 to 24 weeks and fetal heart sounds had been heard immediately prior to delivery and the obstetric team or parents are requesting the presence of a paediatric / neonatal medical officer, it is prudent to be present even though it will most probably be for confirming that the baby is less than 24 weeks gestation (and / or birth weight is $<500 \mathrm{~g}$ ) and therefore not viable, although some signs of life may be present immediately after birth.

$>$ If baby is showing signs of life, keep warm and reassess; if signs of life are present for more than 5 minutes and heart rate is more than $100 / \mathrm{min}$ take the baby to the neonatal unit, to provide comfort care after showing to the mother, and.

If baby shows signs of life but is rapidly deteriorating (in heart rate / breathing) comfort care in the form of keeping warm and being cuddled by the mother (if she wishes) can be provided in the labour room / operation theatre itself after explaining about non-viability of baby to mother. 
- Babies less than ' $24+0$ ' weeks, but with a weight more than $500 \mathrm{~g}$

Less than ' $24+0$ ' weeks, with weight 500-599g

Baby should be kept warm, mask ventilation provided and if heart rate responds, taken to the neonatal unit for further management including clinical assessment of gestational age. If the heart rate does not respond to mask ventilation provide comfort care as described above.

\section{Less than ' $24+0$ ' weeks, and} weight $\geq 600 \mathrm{~g}$

Baby should be kept warm, inflation and ventilation breaths given, and cardiac compressions and adrenaline also provided, if necessary. Adequate resuscitation should not be provided for more than 10 minutes as per Neonatal Life Support guidelines. Clinical assessment of gestational age should be done as soon as possible.

\section{Babies between ' $24+0$ ' and ' $25+6$ ' weeks}

\section{'24+0' to ' $25+6$ ' weeks and weight less than $500 \mathrm{~g}$ \\ Manage as for less than '24+0' with weight less than $500 \mathrm{~g}$}

$>$ '24+0' to ' $25+6$ ' \& weight $500-$ $599 \mathrm{~g}$

Manage as for less than ' $24+0$ ' with weight between $500-599 \mathrm{~g}$

$>\quad 24+0$ ' to ' $25+6$ ' \& weight $\geq 600 \mathrm{~g}$ Manage as for less than ' $24+0$ ' with weight $\geq 600 \mathrm{~g}$

\section{Babies $\geq$ ' $\mathbf{2 6}+\mathbf{+ 0}$ ' weeks gestation}

Resuscitate with inflation breaths, ventilation breaths and adrenaline and cardiac compressions unless the attending paediatrician and other health professionals agree, in consultation with the parents, that the prognosis or outcome is poor on the basis of other scientific and technical reasons. Full intensive care treatment should be offered if the baby stabilizes with initial resuscitation. Document all decisions / consultations with reasons for same, especially if intensive resuscitation is not offered.

Those babies for whom resuscitation is not offered should still be provided comfort care (wrapping / holding by mother if she wishes to) and treated with dignity. It is essential to explain all details to parents and to document the conversation.

If the baby show signs of life (any heart rate and / or breathing) initially and then dies immediately afterwards, the baby should be recorded as a live birth and a neonatal death, with birth and death certificates being issued.

It is recommended to perform a pathological postmortem for all neonatal deaths.

\section{Summary of recommendations}

\section{$>$ Babies $<24$ weeks gestation and $<500 \mathrm{~g}$ \\ $>$ Babies $\geq 26$ weeks gestation and $/$ or $\geq 600 \mathrm{~g}$ \\ : comfort care \\ : full resuscitation \\ $>$ Babies $22+0$ to $25+6$ weeks gestation and $500-599 \mathrm{~g}$ : airway and ventilatory support without cardiac massage and adrenaline}

Clinical assessment of gestational age ${ }^{18}$

The assessment of gestation can be done using the New Ballard score as shown in Figure 1.

For infants less than 26 weeks of gestational age, the greatest validity $(97 \%$ within 2 weeks of first trimester dating scan) was seen when the examination was performed before 12 hours of postnatal age. For infants at least 26 weeks of gestational age, agreement with dating scan averaged at $92 \%$ when examined within 96 hours of birth.

\section{Birth weight of preterm babies}

The birth weight of babies born between 24 to 30 weeks gestation given below are adapted from the UKWHO growth charts, 2013 (Table 2). 
Neuromuscular Maturity

\begin{tabular}{|c|c|c|c|c|c|c|c|}
\hline care & - & 8 & , & ' & 3 & 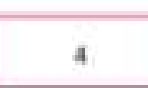 & 5 \\
\hline Postures & & ك & $\cos$ & $\alpha$ & केष्ट & क्रे & \\
\hline 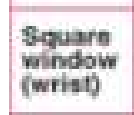 & $\Gamma_{-\infty}$ & $\Gamma_{90}$ & 队 & $\uparrow$. & $A_{3}$ & $\Gamma$ & \\
\hline Acteriat & & 80 & $\mathbb{8}_{10-100}$ & 8 & -8 & $\theta^{\prime}$ & \\
\hline 80 & $\infty_{100}$ & $\hat{D}_{100}$ & के & के & $\sigma_{100}^{3}$ & $\omega_{\infty}$ & $\alpha_{-\infty}$ \\
\hline $\begin{array}{ll}\mathrm{sec} \\
\mathrm{tig}\end{array}$ & -8 & -8 & -8 & -8 & -8 & -8 & \\
\hline 145 & $\oplus$ & $\infty$ & $\infty$ & को & 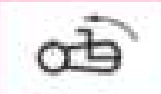 & -3 & \\
\hline
\end{tabular}

\section{Physical Maturity}

\begin{tabular}{|c|c|c|c|c|c|c|c|c|}
\hline 5kin & $\begin{array}{l}\text { Stcky, } \\
\text { frisble, } \\
\text { transpatent }\end{array}$ & $\begin{array}{l}\text { Gelatinous; } \\
\text { red. } \\
\text { tranducent }\end{array}$ & $\begin{array}{l}\text { Simsoth, pind, } \\
\text { visble vens }\end{array}$ & $\begin{array}{l}\text { Bupgrficia: } \\
\text { beoling } \\
\text { andioe rash: } \\
\text { Hew vens }\end{array}$ & $\begin{array}{l}\text { Cracking, } \\
\text { pale andat; } \\
\text { rare vains }\end{array}$ & $\begin{array}{l}\text { Parchinent } \\
\text { deep } \\
\text { cracking. } \\
\text { no vesseds }\end{array}$ & \multicolumn{2}{|c|}{$\begin{array}{l}\text { Leachey } \\
\text { cracked } \\
\text { winkied }\end{array}$} \\
\hline Lanugo & None & Sporse & Aburdant & Thiming & Buld areas & Mostoy bold & \multicolumn{2}{|c|}{$\begin{array}{l}\text { Maturity } \\
\text { fating }\end{array}$} \\
\hline \multirow{3}{*}{$\begin{array}{l}\text { Plantar } \\
\text { surtace }\end{array}$} & \multirow{3}{*}{$\begin{array}{l}\text { Heel toe } \\
40-50 \mathrm{~mm} \\
-1 \\
<40 \mathrm{~mm}:-2 \\
\end{array}$} & \multirow{3}{*}{$\begin{array}{l}>50 \mathrm{~mm} \\
\text { no crease }\end{array}$} & \multirow{3}{*}{$\begin{array}{l}\text { Fand } \\
\text { ced maks }\end{array}$} & \multirow{3}{*}{$\begin{array}{l}\text { Aritebior } \\
\text { trarisvene } \\
\text { stesse only }\end{array}$} & \multirow{3}{*}{$\begin{array}{l}\text { Creases } \\
\text { mienor 2/3 }\end{array}$} & \multirow{3}{*}{$\begin{array}{l}\text { Crokies over } \\
\text { entire acle }\end{array}$} & Score & Wouks \\
\hline & & & & & & & -10 & 20 \\
\hline & & & & & & & -5 & $n$ \\
\hline \multirow[b]{2}{*}{ Breast } & \multirow[b]{2}{*}{ impercepebis } & \multirow{2}{*}{$\begin{array}{l}\text { Bately } \\
\text { perceptible }\end{array}$} & \multirow{2}{*}{$\begin{array}{l}\text { fat acucta. } \\
\text { no bus }\end{array}$} & \multirow{2}{*}{$\begin{array}{l}\text { Btipplind } \\
\text { treola. } \\
1-2 \mathrm{~mm} \text { bud }\end{array}$} & \multirow{2}{*}{$\begin{array}{l}\text { Rainod } \\
\text { aneola. } \\
3-4 \mathrm{~mm} \text { bud }\end{array}$} & \multirow{3}{*}{$\begin{array}{l}\text { Full arkolx. } \\
\text { 5-10 mm bud }\end{array}$} & 6 & 24 \\
\hline & & & & & & & 5 & 26 \\
\hline \multirow{3}{*}{ EyerEmr } & \multirow{3}{*}{$\begin{array}{l}\text { Lag fused } \\
\text { iopsely: }-1 \\
\text { Donfy: }-2\end{array}$} & \multirow{3}{*}{$\begin{array}{l}\text { Lids open: } \\
\text { pirns flat } \\
\text { etarys solosd }\end{array}$} & \multirow{3}{*}{$\begin{array}{l}\text { Shighly } \\
\text { curved pinna: } \\
\text { soft. } \\
\text { siow necol }\end{array}$} & \multirow{3}{*}{$\begin{array}{l}\text { Well curved } \\
\text { penna. } \\
\text { sott but } \\
\text { roby resal }\end{array}$} & \multirow{3}{*}{$\begin{array}{l}\text { Formed and } \\
\text { inth, } \\
\text { instant } \\
\text { recol }\end{array}$} & & 10 & 28 \\
\hline & & & & & & \multirow{2}{*}{$\begin{array}{l}\text { Thick } \\
\text { cartioge. } \\
\text { ear sto. }\end{array}$} & 15 & 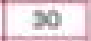 \\
\hline & & & & & & & 20 & 32 \\
\hline \multirow{3}{*}{$\begin{array}{l}\text { Genitais } \\
\text { (male) }\end{array}$} & \multirow{3}{*}{$\begin{array}{l}\text { Serobum tiat. } \\
\text { umoden }\end{array}$} & \multirow{3}{*}{$\begin{array}{l}\text { Scrotum } \\
\text { genpty. } \\
\text { girnt nope }\end{array}$} & \multirow{3}{*}{$\begin{array}{l}\text { Testes in } \\
\text { uppor canal. } \\
\text { rare nagae }\end{array}$} & \multirow{3}{*}{$\begin{array}{l}\text { Testes } \\
\text { dascending. } \\
\text { fow rupae }\end{array}$} & \multirow{3}{*}{$\begin{array}{l}\text { Testes down, } \\
\text { good nagist }\end{array}$} & \multirow{3}{*}{$\begin{array}{l}\text { Testes } \\
\text { pendulous, } \\
\text { deep nope }\end{array}$} & 25 & 34 \\
\hline & & & & & & & 30 & 30 \\
\hline & & & & & & & 35 & 30 \\
\hline \multirow{3}{*}{$\begin{array}{l}\text { Genitais } \\
\text { (femaie) }\end{array}$} & \multirow{3}{*}{$\begin{array}{l}\text { Gitons } \\
\text { prominant. } \\
\text { fagia flat }\end{array}$} & \multirow{3}{*}{$\begin{array}{l}\text { Catseris } \\
\text { prominent. } \\
\text { small } \\
\text { Gata minora }\end{array}$} & \multirow{3}{*}{$\begin{array}{l}\text { Cibris } \\
\text { prominant. } \\
\text { onlarging } \\
\text { minota }\end{array}$} & \multirow{3}{*}{$\begin{array}{l}\text { Majora and } \\
\text { mincra } \\
\text { oquasty } \\
\text { prominent }\end{array}$} & \multirow{3}{*}{$\begin{array}{l}\text { Majora lasge. } \\
\text { michora smat }\end{array}$} & \multirow{3}{*}{$\begin{array}{l}\text { Majoca cover } \\
\text { cliboris and } \\
\text { minora }\end{array}$} & 40 & 40 \\
\hline & & & & & & & 45 & 42 \\
\hline & & & & & & & 50 & 44 \\
\hline
\end{tabular}

Figure 1: New Ballard Score ${ }^{18}$

Table 2: Birth weight of preterm babies as per the UK-WHO growth charts (2013) ${ }^{19}$

\begin{tabular}{|c|c|c|c|c|c|c|}
\hline \multirow[t]{3}{*}{ Period of gestation } & \multicolumn{6}{|c|}{ Birth weight (g) } \\
\hline & \multicolumn{3}{|c|}{ Centiles (Girls) } & \multicolumn{3}{|c|}{ Centiles (Boys) } \\
\hline & $9^{\text {th }}$ & $50^{\text {th }}$ & $91^{\text {st }}$ & $9^{\text {th }}$ & $50^{\text {th }}$ & $91^{\text {st }}$ \\
\hline 24 weeks & 500 & 650 & 800 & 550 & 710 & 940 \\
\hline 25 weeks & 575 & 760 & 940 & 625 & 810 & 1075 \\
\hline 26 weeks & 650 & 860 & 1175 & 710 & 910 & 1225 \\
\hline 27 weeks & 725 & 975 & 1325 & 800 & 1025 & 1375 \\
\hline 28 weeks & 800 & 1090 & 1500 & 875 & 1150 & 1550 \\
\hline 29 weeks & 900 & 1210 & 1675 & 975 & 1275 & 1750 \\
\hline 30 weeks & 1000 & 1300 & 1875 & 1075 & 1425 & 1950 \\
\hline
\end{tabular}




\section{Optimising the care of extremely preterm infants}

- If a mother whose gestation is unsure but appears to be close to the limits of viability or the known gestation is close to the limits of viability, and she is in labour, it is suggested that she be admitted to the antenatal ward (rather than gynaecology ward) and be taken to the labour room for the birth in order to provide the baby with the optimal set-up of personnel and equipment to achieve early stabilisation / comfort care as appropriate.

- Antenatal steroids should be administered to the mother as per National Guidelines with minimal delay when an eligible pregnant mother presents in labour or is likely to need delivery within the next week. This will give the longest possible time for the baby to reap the benefits of the steroids prior to delivery, of a reduced risk of death, respiratory distress syndrome and intraventricular haemorrhage.

- Magnesium sulphate should be given to mothers in the eligible gestations, when delivery is imminent, as per National Guidelines, in order to reduce the incidence of cerebral palsy in a category of preterm babies.

\section{Transfer of preterm neonates}

Extremely preterm infants have a high rate of mortality and morbidity both of which increase with the baby being smaller and of a lesser gestation. Transport of these infants even in the most ideal conditions with the availability of transport incubators, transport ventilators and trained personnel from a tertiary unit (who even attend the delivery of the baby) it is proven and well known that these babies have much worse outcomes than inborn babies of the same hospital ${ }^{20}$. Even a moderate drop in body temperature during transport is a significant independent risk factor for poor outcomes in preterm infants.

Therefore, if time permits, the best method of transferring a neonate is to do so before delivery, while the baby is still in-utero ${ }^{21}$, if facilities in equipment or personnel are not available in the particular hospital that the mother has currently presented to. This should be done by the obstetric team following consultation with the neonatal / paediatric team of the hospital where the mother is currently in and most importantly in consultation with the receiving hospital obstetric and neonatal teams.

In the event that the mother's presentation does not allow adequate time for an in-utero transfer, and once the baby is born it is evident that available facilities (technological and personnel) in that particular hospital are not adequate to care for the baby, the prevailing situation should be discussed with the parents. It should be explained very clearly that transport is one of the most risky and destabilising activities for a preterm baby, with the risk of associated poor outcomes increasing exponentially, the smaller and more preterm a baby is.

Therefore parents need to understand that transporting the baby per se can result in death or poor long term outcomes and that being transferred to a unit that has the technological equipment and personnel trained in caring for such a baby does not herald the resolution and cure of all problems; it might actually result in the beginning of events that ultimately lead to death or severe neuro-disability.

It is vital that the decision to transport is therefore made in collaboration with the parents and a signature obtained to a written statement regarding same. The decision to offer transfer to an extremely preterm / low birth weight baby should be made on an individual basis taking into consideration the baby's weight and estimated gestation, any congenital anomalies, along with current haemodynamic / respiratory stability. The transfer option should be offered to the parents by the attending clinician if he / she is of the opinion that the baby has a reasonable chance of survival with minimal disability taking into consideration possible instability en-route as well. The already high risk of mortality and morbidity with the additional risk of transport should be explained to parents. Until the baby is ultimately transferred advice regarding management can be obtained from the receiving hospital.

\section{Recommendations for Ministry of Health (MoH), Sri Lanka}

1. Sri Lanka College of Paediatricians (SLCP) recommends the $\mathrm{MoH}$ to take steps to achieve universal coverage of the agreed policy on early ultrasound scans for dating in order to accurately determine gestational age to help implement these guidelines.

2. SLCP recommends the $\mathrm{MoH}$ to take immediate action to implement the agreed policy on creating the National perinatal databases and surveillance to determine outcome of ELBW infants in Sri Lanka.

3. SLCP recommends the $\mathrm{MoH}$ to take immediate action to amend the outdated law 
which can be used to penalise health care providers in the current setting.

4. SLCP recommends that resources be made available in the form of facilities and trained personnel for performing post-mortems in the event of all neonatal deaths.

\section{References}

1. Penal code of Sri Lanka (as amended). Available from: http://www1.umn.edu/humanrts/research/sril anka/statutes/Penal_Code.pdf

2. Institute of Medicine (US) Committee on Understanding Premature Birth and Assuring Healthy Outcomes; Behrman RE, Butler AS, editors. Washington (DC): National Academies Press (US); 2007. Preterm Birth: Causes, consequences \& prevention. Accessed 25th October 2014. Available at http://www.ncbi.nlm.nih.gov/books/NBK11 $\underline{362 / \mathrm{pdf} / \mathrm{TOC} . \mathrm{pdf}}$

3. American College of Obstetricians and Gynaecologists, Committee Opinion No 611: Method for estimating Due Date. Obstetrics \& Gynecology 2014; 124(4):863-6.

4. Powell TL et al, Decisions and dilemmas related to resuscitation of infants born on the verge of viability. Newborn and Infant Nursing Reviews 2012;12(1):27-32 http://dx.doi.org/10.1053/j.nainr.2011.12.004

5. Oxford dictionaries. Accessed on October 25, 2014. Available at:

http://www.oxforddictionaries.com/definitio $\underline{\mathrm{n} / \mathrm{english} / \mathrm{viable}}$

6. Merriam-Webster, Merriam-Webster online. Viability. Accessed on October 25, 2014.

Available at:

http://www.merriamwebster.com/dictionary/ viability

7. Seri I, Evans J. Limits of viability: definition of the gray zone. Journal of Perinatology 2008; 28:S4-S8.

http://dx.doi.org/10.1038/jp.2008.42

8. Rushing S, Ment LR. Preterm birth: a cost benefit analysis. Seminars in Perinatology 2004;28:444-50 http://dx.doi.org/10.1038/jp.2008.42
9. Aksit M, Antsakli A, Arabin B, Bancalari E, Carbonell X, Carrapato M. Ethical dimensions of periviability. Journal of Perinatal Medicine 2010; 38:579-89.

10. WHO and UNICEF. Every Newborn: An action plan to end preventable deaths, 2014. Available from:

http://www.merckformothers.com/docs/Ever y-Woman-Every-Child Every-Newborn.pdf

11. WHO: Health statistics and Information systems, 2014. Accessed on October 26 2014. Available at:

http://www.who.int/healthinfo/statistics/ind maternalmortality/en/

12. Feto-maternal mortality surveillance, Ministry of Health, Sri Lanka. Available from:

http://www.familyhealth.gov.lk/web/index.p hp?option $=$ com phocadownload\&view $=$ cat egory\&id=8\&Itemid=93\&lang $=$ en

13. Wood NS, Marlow N, Costeloe K, Gibson AT, Wilkinson AR. Neurologic and developmental disability after extremely preterm birth. EPICure study group. The New England Journal of Medicine 2000; 343(6): 378-84.

http://dx.doi.org/10.1056/NEJM2000081034 30601

14. Moore T, Hennessy EM, Myles J, Johnson SJ, Draper ES, Costeloe KL, Marlow N. Neurological and developmental outcome in extremely preterm children born in England in 1995 and 2006: the EPICure studies. British Medical Journal 2012;345:e7961 http://dx.doi.org/10.1056/NEJM2000081034 $\underline{30601}$

15. Wilkinson AR, Ahluwalia J, Cole A, Crawford D, Fyle J, Gordon A et al. Management of babies born extremely preterm at less than 26 weeks of gestation: A framework for clinical practice at the time of birth. Archives of Diseases in Children Fetal Neonatal Ed 2009; 94:2-5 http://dx.doi.org/10.1136/adc.2008.143321

16. Synnes AR, Buchanan L, Ruth C, Albersheim S. Management of the newborn delivered at the threshold of viability. $B C$ Medical Journal, 2008; 50(9): 498-508 
17. Kattwinkel J, Perlman JM, Aziz K, et al.Neonatal resuscitation: 2010 American Heart Association guidelines for cardiopulmonary resuscitation and emergency cardiovascular care. Pediatrics 2010; 126:1400.

http://dx.doi.org/10.1542/peds.2010-2972E

18. Ballard JL1, Khoury JC, Wedig K, Wang L, Eilers-Walsman BL, Lipp R. New Ballard Score, expanded to include extremely premature infants. Journal of Pediatrics 1991; 119(3):417-23.

http://dx.doi.org/10.1016/S00223476(05)82 $\underline{056-6}$

19. Royal College of Paediatrics and Child Health. $2^{\text {nd }}$ edition. 2013. Available from: http://www.rcpch.ac.uk/childhealth/standard s-care/nutrition-and-growth/uk-who-growthcharts/uk-who-growth-chart-resources
20. Palmer KG1, Kronsberg SS, Barton BA, Hobbs CA, Hall RW, Anand KJ. Effect of inborn versus out born delivery on clinical outcomes in ventilated preterm neonates: secondary results from the NEOPAIN trial. Journal of Perinatology 2005; 25(4):270-5. http://dx.doi.org/10.1038/sj.jp.7211239

21. Chien L et al. Improved outcome of preterm infants when delivered in tertiary care centres. Obstetrics \& Gynecology 2001; 98(2):247-52.

http://dx.doi.org/10.1016/S00297844(01)01 438-7 